\title{
Manual versus automatic indices assessment based on a marker-less, three dimensional, structural light surface topography postural evaluation. Preliminary study
}

\author{
W Glinkowski ${ }^{*}$, J Michoński², B Glinkowska ${ }^{3}$, R Sitnik $^{2}$ \\ From 9th International Conference on Conservative Management of Spinal Deformities - SOSORT 2012 \\ Annual Meeting \\ Milan, Italy. 10-12 May 2012
}

\section{Background}

Posterior Trunk Symmetry (POTSI) and Deformity in the Axial Plane (DAPI) Indices, and sagittal plane curvature measurements, are frequently used to measure deformities.

\begin{abstract}
Aim
The aim of this study was to perform a preliminary assessment, and a reliability test, of the algorithm designed to provide a more reliable way of localizing anatomical back shape landmarks for school screening subjects.
\end{abstract}

\section{Methods}

A 3D Orthoscreen system, designed for postural deformity telediagnostics, using the structural light method, was used for school screening [2,3]. Clouds of dots were acquired for every subject. POTSI, DAPI, kyphosis and lordosis were measured, after marker-less landmarking of anatomical back structures, manually and automatically, for the same subjects. 50 subjects were assessed, 22 male adolescent subjects (average age 15.18 years - from 14 to 17 ) and 28 females (average age 14.55 - from 14 to 16 ) were examined. Their clouds of dots were acquired and saved. Clouds were retrieved and analyzed utilizing 3D Orthoscreen system. An operator (trained professional) retrieved 3D data and analyzed by pointing landmarks manually or automatically. After landmarking, procedure

'Department of Orthopaedics and Traumatology of Locomotor System, Center of Excellence "TeleOrto", Medical University, Warsaw, Poland Full list of author information is available at the end of the article
Indices and angular measurements were calculated by the system. MedCalc statistical software (Version 12.1.4.0) was used to calculate Inter-rater correlation for measurements.

\section{Results}

Intra-class correlation coefficients, for manual and automatic raters, were calculated for all assessed parameters. Strong, and almost perfect, agreement was found for sagittal plane curvature measurements (kyphosis and lordosis). The Intra-class correlation at 95\% Confidence Interval for Kyphosis, Automatic vs. Manual measurements, for average measures was 0.87 (from 0.77 to 0.92), and Lordosis, Automatic vs. Manual measurements, for average measures 0.958 (from 0.9261 to 0. 9761), POTSI, Automatic vs. Manual, for average measures 0.72 (from 0.49 to 0.84 ). ICC for DAPI Automatic vs. Manual measurements was $0.02-0.047$.

\section{Conclusion}

Strong, and almost perfect, agreement we found for sagittal plane curvature measurements (kyphosis and lordosis) may coincide with the method of measurement (Debrunner like method). Fair agreement for POTSI Index, and poor for DAPI, was found in this preliminary series. It may depend on the formula used for Index's calculation. Further studies, and development of the algorithm, and source of inadequacies, shall be considered to improve automatic calculation reliability.

\section{Author details}

${ }^{1}$ Department of Orthopaedics and Traumatology of Locomotor System,

Center of Excellence "TeleOrto", Medical University, Warsaw, Poland. 'Institute 
of Micromechanics and Photonics, Warsaw University of Technology, Warsaw, Poland. ${ }^{3}$ Department of Sport and Physical Education, Medical University of Warsaw, Warsaw, Poland.

Published: 3 June 2013

\section{References}

1. Patias P, Grivas TB, Kaspiris A, Aggouris C, Drakoutos E: A review of the trunk surface metrics used as Scoliosis and other deformities evaluation indices. Scoliosis 5:12.

2. Glinkowski W, Wojciechowski A, Sitnik R, Witkowski M, Glinkowska B, Golebiowski M, Gorecki A: Postural 3D Kyphosis assessment, back pain and QCT in Osteoporotic vertebral compression fracture cases: Preliminary study. Osteoporosis International 2010, 21:383-383.

3. Glinkowski W, Kabacyj M, Sliwka A, Wiacek P, Twardowska K, R S: Reproducibility of Structural Light Assessment 3D Posture Telediagnostic: Preliminary Reliability Study. Global Telemedicine and eHealth Updates: Knowledge Resources 2011, 4:154-157.

4. Michonski J, Glinkowski W, Witkowski M, R S: Automatic recognition of surface landmarks of anatomical structures of back and posture. J Biomed Opt 2012, 17(5):056015.

doi:10.1186/1748-7161-8-S1-024

Cite this article as: Glinkowski et al:: Manual versus automatic indices assessment based on a marker-less, three dimensional, structural light surface topography postural evaluation. Preliminary study. Scoliosis 2013 8(Suppl 1):O24

\section{Submit your next manuscript to BioMed Central} and take full advantage of:

- Convenient online submission

- Thorough peer review

- No space constraints or color figure charges

- Immediate publication on acceptance

- Inclusion in PubMed, CAS, Scopus and Google Scholar

- Research which is freely available for redistribution

Submit your manuscript at www.biomedcentral.com/submit 